\title{
Simultaneous Estimation of Etophylline and Theophylline in Bulk and solid Dosage Form by Chemometric Assisted Spectrophotometric Methods
}

\author{
S.Nagajyothi*, A. Elphine Prabahar, P.V.Suresh, RamaRao Nadendla \\ Department of pharmaceutical analysis, chalapathi institute of pharmaceutical sciences ,lam Guntur.
}

\begin{abstract}
A simple UV-visible spectroscopic method was developed and Chemometric designs were applied for the simultaneous estimation of Etophylline (ETO) ,Theophylline (THEO) in bulk and solid dosage form. The spectroscopic method was developed by using methanol as solvent for the two drugs and the data generated from the spectra were mined by using Chemometric methods such as bi-linear regression analysis, Cramer's matrix method and Method of least squares.The wavelengths selected for all the above methods were $271 \mathrm{~nm}$ (wavelength of maximum absorption; $\lambda$ max of ETO), $273 \mathrm{~nm}$ (wavelength of maximum absorption; $\lambda$ max of THEO).

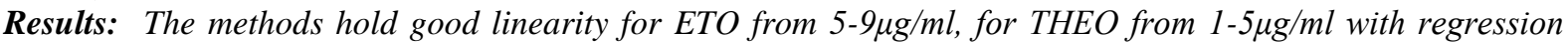
coefficient values of 0.999/ 0.998 respectively. The RSD for interday and inter-day precision was found to be less than $2 \%$. The percentage recovery and percentage assay was in the range 95-115\% Of for Etophylline (ETO) and Theophylline (THEO) by all the methods.

Conclusion: The developed methods neither require any cumbersome separation procedure nor complex derivatization procedures for the analysis of the two drugs and moreover they are effective in minimizing the errors in analysis, simple and economical.
\end{abstract}

Keywords:- $\boldsymbol{U V}$-visible spectroscopy, Etophylline, Theophylline.

\section{Introduction}

Chemo metrics is the science of extracting information from chemical systems by data-driven means. Chemometrics is inherently interdisciplinary, using methods frequently employed in core data-analytic disciplines such as multivariate statistics, applied mathematics, and computer science, in order to address problems in chemistry, biochemistry, medicine, biology and chemical engineering. (1)In this way, it mirrors other interdisciplinary fields, such as psychometrics(5) and chemo metrics can be applied to be solve both descriptive and predictive problems in experimental natural sciences like in chemistry applications and there properties (6).these two chemo metrics techniques are used as analytical chemistry and the development of chemo metric methods.(2.Chemometrics can be described as the interaction of mathematical and statistical methods to chemical analysis and problems chemometric has developed because of the changes in the enormous data and in which data is obtained in chemistry along with the evaluation of new analytical Technique's along with the computer technology.(4)

The development of computer technology has been tremendously cause the wide growth of chemo metrics.(7 Majority of the methods can be utilized in the chemometrics depend upon the ability and capacity of computer to perform the large calculations.(8)In the analytical chemistry chemo metrictechniques has its applications in spectroscopy like uv-visible spectroscopy, IR-spectroscopy, fluorescence, chromatograph like liquid chromatography and also various analytical chemistry like flow injection analysis in pharmaceutical preparations(10).

Chemo metrics methods are like:-

1. Bi-linear regression analysis.

2. Cramer's matrix method.

3. Method of least squares.

Principles of chemo metrics are as followed by:-

1. Chemometrics are use mathematical models for the connection, rationalization and interpretation of chemical data obtained by analysis.

2. These are include variability in the model, and handle the variability by means of distribution.

3. These are use statistical designs for planning sets of experiments when need to change conditions or optimizing etc. rather than changing only one factor and keeping others fixed.

4. Always to be use multivariate data analysis methods and show results as plots also perform the validation of mathematical model 
1. Etophylline:-IUPAC name: -7-(2-Hydroxyethyl)-1, 3-dimethyl-3, 7-dihydro-1H-purine-2, 6Dione;Mol.wt:-329.310g/mol.

2. Theophylline IUPAC name :- 1, 3-dimethyl-3, 7-dihydro-1H- purine-2, 6-dione;mol.wt:-180.16 g/mol

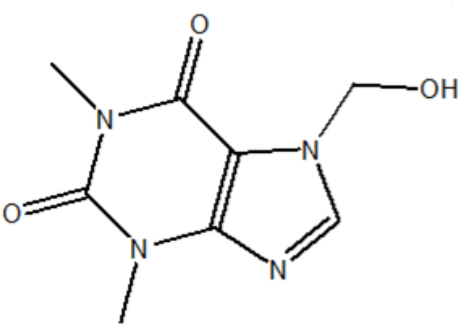

Etophylline

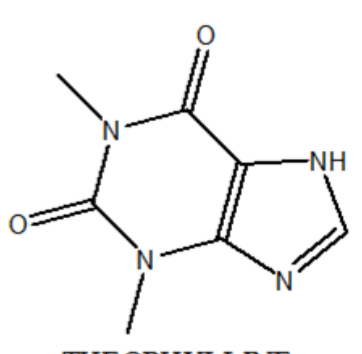

THEOPHYLLINE

Fig:-1.Etophylline Structure like Theophylline $(\mathrm{R}=\mathrm{H})$ fig:-2.Etophylline $(\mathrm{R}=\mathrm{CH} 3 \mathrm{CH} 2 \mathrm{OH})$.

Etophylline and Theophylline are the non-selective phosphor diesterase inhibitor, anti-asthmatic agent used in the treatment of acute attacks or status asthmatic in conjunction with other drugs. Theophylline is respiratory smooth muscle relaxant, phosphor di-esterase inhibitor, bronchodilator agent and vasodilator agent. Chemically it is 1, 3-dimethyl-3, 7-dihydro-1H- purine-2, 6-dione.Literature survey revealed that Etophylline and Theophylline in combination with other drugs were simultaneously estimated by HPLC literature survey also revealed that HPLC and HPTLC methods have been reported for the simultaneous estimation of etophylline and theophylline in combined dosage forms. No UV spectrophotometric method has been reported for simultaneous determination of Etophylline and Theophylline in combined dosage form. The present article discusses the attempts made to develop simple, sensitive, reproducible and economical chemo metric methods for simultaneous determination of these drugs in combined dosage forms. Etophylline and theophylline both the drugs have same chromosphere and complete overlapping spectra Hence they cannot be quantified with any conventional UV method.by using different chemo metric methods.

Instruments are used:

\section{Materials And Methods:}

- Analytical balance

- UV-Visible spectrophotometer (Lab India -3072)

\section{Data handling systems:}

- UV-Win for the handling of spectrophotometer.

- Microsoft Excel.

- $\quad$ Easy Matrix Calculator Pro (Ver. 5.4) were used for resolving the data matrices.

- Chem diagram

\section{Materials used:}

These Working standard drugs are procured from Dr. Reddy s laboratory.

Commercial formulation of drugs were purchased from local market. Methanol AR grade was procured from Merck (India) ltd, Mumbai.

\section{PREPARATION STANDARED SOLUTIONS}

Preparation of Etophylline standard solution:- 10mg of Etophylline (API) was dissolved in methanol and concentrations of $5,6,7,8,9 \mu \mathrm{g} / \mathrm{ml}$ was prepared in $10 \mathrm{ml}$ of volume metric flask and make up with methanol. Observe in uv-visible spectroscopy at $273 \mathrm{~nm}$.

Preparation of Theophylline standard solution :10mg of theophylline (API) was dissolved in methanol and concentrations of $1,2,3,4,5 \mu \mathrm{g} / \mathrm{ml}$ was prepared in $10 \mathrm{ml}$ of volume metric flask and make up with methanol. Observe in uv-visible spectroscopy at $271 \mathrm{~nm}$.

\section{PREPARATION OF FORMULATION /TEST SOLUTION}

Preparation of Etophylline, Theophylline solutions

By preparing the formulation based on the label claim take $24.2 \mathrm{mg}$ (formulation) was take and dissolved in $5 \mathrm{ml}$ of methanol then made up to $10 \mathrm{ml}$ with methanol $(10 \mathrm{ml}$ volumetric flask $/ 1000 \mu / \mathrm{ml})$ then take into the above solution $0.1 \mathrm{ml}$ then make up into $10 \mathrm{ml}$ with methanol take from above solution take $5 \mathrm{ml}$ then make up with methanol up to $10 \mathrm{ml}$ (5 conc ) was observed in uv-visible spectroscopy at 200-400nm. 
DESIGN OF CHEMOMETRIC MODELS:-

Chemometric models were designed for the developed spectrophotometric methods for the simultaneous estimation of etophylline (ETO) theophylline (THEO).

Linear Regression Component (LRC) method:-In this method three wavelengths were considered for the analysis of the component mixtures are like [ETO;THEO].The bi- linear regression equations were obtained by using the absorbance measured at three wavelengths against concentrations of standard solutions for each component. The slope values obtained from the linear regression analysis for each component were used for the formation of matrix set.

The wavelengths selected for analysis were 271 ( $\lambda_{\max }$ of theo ), $273 \mathrm{~nm}$ ( $\lambda_{\max }$ of THEO).

Equations for the formation of matrix are:-

$$
\begin{aligned}
& A_{\text {mix } 1}=b_{x 1} C_{x}+b_{y 1} C_{y}+a_{x y 1} \\
& A_{\text {mix } 2}=b_{x 2} C_{x}+b_{y 2} C_{y}+a_{x y 2}
\end{aligned}
$$

Where, $\mathbf{A}_{\text {mix } 1}, \mathbf{A}_{\text {mix } 2}$ are the absorbance of the mixture of $\mathrm{X}, \mathrm{Y}$ analytics at three wavelengths set. $\mathbf{a}_{\mathbf{x y} 1}, \mathbf{a}_{\mathbf{x y} 2}$ are the sum of intercepts of the linear regression equation at the three wavelengths.

Conversion of equation into matrix form:

$$
\left[\begin{array}{ll}
\text { Amixl- } & \text { axyl } \\
\text { Amix2- } & \text { axy2 }
\end{array}\right]=\left[\begin{array}{ll}
\text { bx } 1 & \text { byl } \\
\text { bx } 2 & \text { by } 2
\end{array}\right] \times\left[\begin{array}{l}
\mathrm{Cx} \\
\mathrm{Cy}
\end{array}\right]
$$

\section{Cramer's Matrix Method}

Molar absorptivity $(\varepsilon)$ values were calculated by using the absorbance measured at $271 \mathrm{~nm}, 273 \mathrm{~nm}$, for each compound in the bi mixture. The selected wavelength values were $\lambda_{\max }$ of ETO, and THEO respectively. By using absorptivity $(\varepsilon)$ values, a system of equations with three unknowns is the bi mixture have been written as follows:

$$
\begin{aligned}
& \mathrm{A}_{\mathrm{m}, 271}=\varepsilon_{\mathrm{Te}, 271} \mathrm{C}_{\mathrm{Te}}+\varepsilon_{\mathrm{Et} 271} \mathrm{C}_{\mathrm{te}} \\
& \mathrm{A}_{\mathrm{m}, 273}=\varepsilon \mathrm{te}, 273 \mathrm{CTe}+\varepsilon_{\mathrm{Et}, 273} \mathrm{C}_{\mathrm{Te}}
\end{aligned}
$$

Where $A_{m}$ denotes the absorbance of the Two mixture and $\varepsilon$ represents the values of molar absorptivity for the calculated, ETO, THEO respectively at $271 \mathrm{~nm}, 273 \mathrm{~nm}$. is the molar concentration of ETO,THEO.

The matrix simplifies and solves the system of equations with three unknowns as follows:

This matrix can be solved and each compound was determined by solving the following operations

$$
\begin{aligned}
& \text { ( } \Delta=\text { Determinant value of matrix) } \\
& \Delta=\left[\begin{array}{ll}
{ }^{\varepsilon} \text { Eto273 } & { }^{\varepsilon} \text { Theo273 } \\
\varepsilon \text { Eto271 } & \varepsilon \text { Theo271 }
\end{array}\right] \\
& \Delta_{1}=\left[\begin{array}{ll}
\text { Am271 } & { }^{\varepsilon E t o 271} \\
\text { Am273 } & { }^{\varepsilon} \text { Eto273 }
\end{array}\right] \\
& \Delta_{2}=\left[\begin{array}{ll}
\text { ETheo271 } & \text { Am271 } \\
\varepsilon \text { Theo273 } & \text { Am273 }
\end{array}\right]
\end{aligned}
$$

By applying Cramer's matrix rule the concentration ETO and THEO can be found by

$$
\mathrm{C}_{\mathrm{ETO}}=\Delta_{1} / \Delta \quad \mathrm{C}_{\mathrm{THEO}}=\Delta_{2} / \Delta
$$

\section{Method of Least Squares}

The standard stock solutions of ETO $(8 \mu \mathrm{g} / \mathrm{ml})$ and THEO $(2 \mu \mathrm{g} / \mathrm{ml})$ were measured at $250 \mathrm{~nm}, 254 \mathrm{~nm}$, $258 \mathrm{~nm}, 262 \mathrm{~nm}, 266 \mathrm{~nm}, 270 \mathrm{~nm}, 274 \mathrm{~nm}, 278 \mathrm{~nm}$,) and their absorbance's were recorded (acts as calibration set) and tabulated in MS- Excel. The individual drug absorbance of known concentrations of ETO and THEO were added and synthetic mixture (as validation set) was created and absorbance were recorded. Similarly the test sample was also measured at same wavelengths and absorbance's were recorded and tabulated. By applying method of least squares using Solver add-in in MS-Excel, the actual concentration ofETO and THEOwere predicted in test samples.

Validation of spectrophotometric method:

Linearity and range:-

The linearity of analytical method is its ability to obtain test results which are directly proportional to the concentration of analyte in the sample. 
The range of analytical procedure is the interval between the upper and lower concentrations of the sample for which the analytical procedure has a suitable level of Precision, Accuracy and Linearity.

\section{Precision:}

The precision of analytical procedure expresses the closeness of agreement between a series of measurements obtained from multiple sampling of the same homogeneous sample under the prescribed conditions.

\section{Accuracy:}

The accuracy of analytical procedure express the closeness or agreement between the value which is accepted either as a conventional true value or an accepted reference value and the value found. The accuracy of the method was determined by adding known quantities of analyte (pure drug) to the drug product and applying the developed methods to determine the quantity of the drug present in the spiked sample. Samples were spiked with $75 \% 100,125 \%$ level solutions of the standards and analysed. The experiment was performed triplicate $(n=3)$. Percent recovery values were reported.

$$
\text { Accuracy }=\frac{\text { Amount of Sample Conc. found }- \text { Amount of Test Conc. taken }}{\text { Amount of Standard Conc. added }} \times 100
$$

Assay:

The commercial marketed formulation containing Etophylline of $8.7 \mathrm{mg}$.and Theophylline of $2.3 \mathrm{mg}$. The sample solution was treated same as standard solution. The resulting solution scanned under UV using methanol as blank.

$$
\text { Percent Assay }=\frac{\text { Calculated qty of test sample }(\mathrm{mg})}{\text { Weight of test sample }(\mathrm{mg})} \times 100
$$

\section{Bi -linear regression analysis:}

\section{Results And Discussion}

Table No.1: Absorbance of Etophylline at $273 \mathrm{~nm}, 271 \mathrm{~nm}$.

\begin{tabular}{|lll|}
\hline Conc. $(\mu \mathrm{g} / \mathrm{ml})$ & $273 \mathrm{~nm}$ & $271 \mathrm{~nm}$ \\
\hline 5 & 0.253 & 0.051 \\
\hline 6 & 0.331 & 0.062 \\
\hline 7 & 0.348 & 0.073 \\
\hline 8 & 0.443 & 0.082 \\
\hline 9 & 0.473 & 0.094 \\
\hline Linear Equation & $\mathrm{y}=0.055 \mathrm{x}+0.016$ & $\mathrm{y}=0.010 \mathrm{x}-0.001$ \\
\hline $\mathrm{R}^{2}$ & 0.963 & 0.998 \\
\hline
\end{tabular}

Table No.2 : Absorbance of Theophylline at $271 \mathrm{~nm}$ and $273 \mathrm{~nm}$

\begin{tabular}{|lll|}
\hline Conc. $(\mu \mathrm{g} / \mathrm{ml})$ & $271 \mathrm{~nm}$ & $273 \mathrm{~nm}$ \\
\hline 1 & 0.072 & 0.009 \\
\hline 2 & 0.117 & 0.018 \\
\hline 3 & 0.184 & 0.032 \\
\hline 4 & 0.186 & 0.040 \\
\hline 5 & 0.356 & 0.049 \\
\hline Linear Equation & $\mathrm{y}=0.063 \mathrm{x}+0.008$ & $\mathrm{y}=0.010 x+0.001$ \\
\hline $\mathrm{R}^{2}$ & 0.970 & 0.991 \\
\hline
\end{tabular}

$$
\begin{gathered}
{\left[\begin{array}{cc}
\text { Amixl- } & \text { axyl } \\
\text { Amix2- } & \text { axy2 }
\end{array}\right]=\left[\begin{array}{ll}
\mathrm{bx} 1 & \mathrm{by} 1 \\
\mathrm{bx} 2 & \mathrm{by} 2
\end{array}\right] \times\left[\begin{array}{l}
\mathrm{Cx} \\
\mathrm{Cy}
\end{array}\right]} \\
{\left[\begin{array}{ll}
0.443 & 0.024 \\
0.135 & 0.002
\end{array}\right]=\left[\begin{array}{ll}
0.055 & 0.0063 \\
0.010 & 0.010
\end{array}\right] \times\left[\begin{array}{l}
\mathrm{Cx} \\
\mathrm{Cy}
\end{array}\right]} \\
{\left[\begin{array}{l}
\mathrm{Cx} \\
\mathrm{Cy}
\end{array}\right]=\left[\begin{array}{l}
8.269 \\
2.731
\end{array}\right]}
\end{gathered}
$$

The concentration of Etophylline $\left(\mathrm{C}_{\mathrm{x}}\right)$, and Theophylline $\left(\mathrm{C}_{\mathrm{y}}\right)$ present in the given formulation sample were found to be $8.26 \mu \mathrm{g} / \mathrm{ml}$, and $2.731 \mu \mathrm{g} / \mathrm{ml}$.

\section{Cramer's matrix method:}

$$
\begin{aligned}
& \mathrm{A}_{\mathrm{m}}, 271=\varepsilon_{\mathrm{Te}, 271} \mathrm{C}_{\mathrm{Te}}+\varepsilon_{\mathrm{Et} 271} \mathrm{C}_{\mathrm{te}} \\
& \mathrm{A}_{\mathrm{m}, 273}=\varepsilon \mathrm{te},{ }_{273} \mathrm{CTe}+\varepsilon_{\mathrm{Et}, 273} \mathrm{C}_{\mathrm{Te}}
\end{aligned}
$$




$$
\left[\begin{array}{l}
A m, 271 \\
A m, 273
\end{array}\right]=\left[\begin{array}{ll}
\varepsilon \text { theo, } 271 & \varepsilon \text { eto, 273 } \\
\varepsilon \text { theo, } 273 & \varepsilon \text { eto, 271 }
\end{array}\right] \times\left[\begin{array}{c}
\text { C eto } \\
C \text { theo }
\end{array}\right]
$$

By substituting the values in matrix and it was solved and each compound was determined by solving the following operations ( $\Delta=$ Determinant value of matrix).

$$
\begin{aligned}
\Delta & =\left[\begin{array}{ll}
10250 & 44000 \\
59125 & 8800
\end{array}\right] \\
\Delta_{1} & =\left[\begin{array}{cc}
0.472 & 44000 \\
0.110 & 8800
\end{array}\right] \\
\Delta_{2} & =\left[\begin{array}{ll}
10250 & 0.380 \\
59125 & 0.110
\end{array}\right]
\end{aligned}
$$

By applying Cramer's matrix rule the concentration of ETOand THEO were found as follows;

$$
\begin{aligned}
\mathrm{C}_{\text {eto }}=\Delta_{1} / \Delta & =8.469 \mu \mathrm{g} / \mathrm{Ml} \\
\mathrm{C}_{\text {theo }}= & \Delta_{2} / \Delta \\
=2.733 \mu \mathrm{g} / \mathrm{mL} &
\end{aligned}
$$

The concentration of Etophylline $\left(\mathrm{C}_{\mathrm{x}}\right)$, and Theophylline $\left(\mathrm{C}_{\mathrm{y}}\right)$ present in the given formulation sample were found to be $8.7 \mu \mathrm{g} / \mathrm{ml}, 2.39 \mu \mathrm{g} / \mathrm{ml}$ respectively.

\section{Method of least squares:}

The standard stock solutions of ETO $(8.4 \mu \mathrm{g} / \mathrm{mL})$, THEO $(2 \mu \mathrm{g} / \mathrm{mL})$, were measured at $240-280 \mathrm{~nm}$ with $4 \mathrm{~nm}$ interval. Molar absorptivity's are calculated and tabulated. Further calculations are done as shown below.

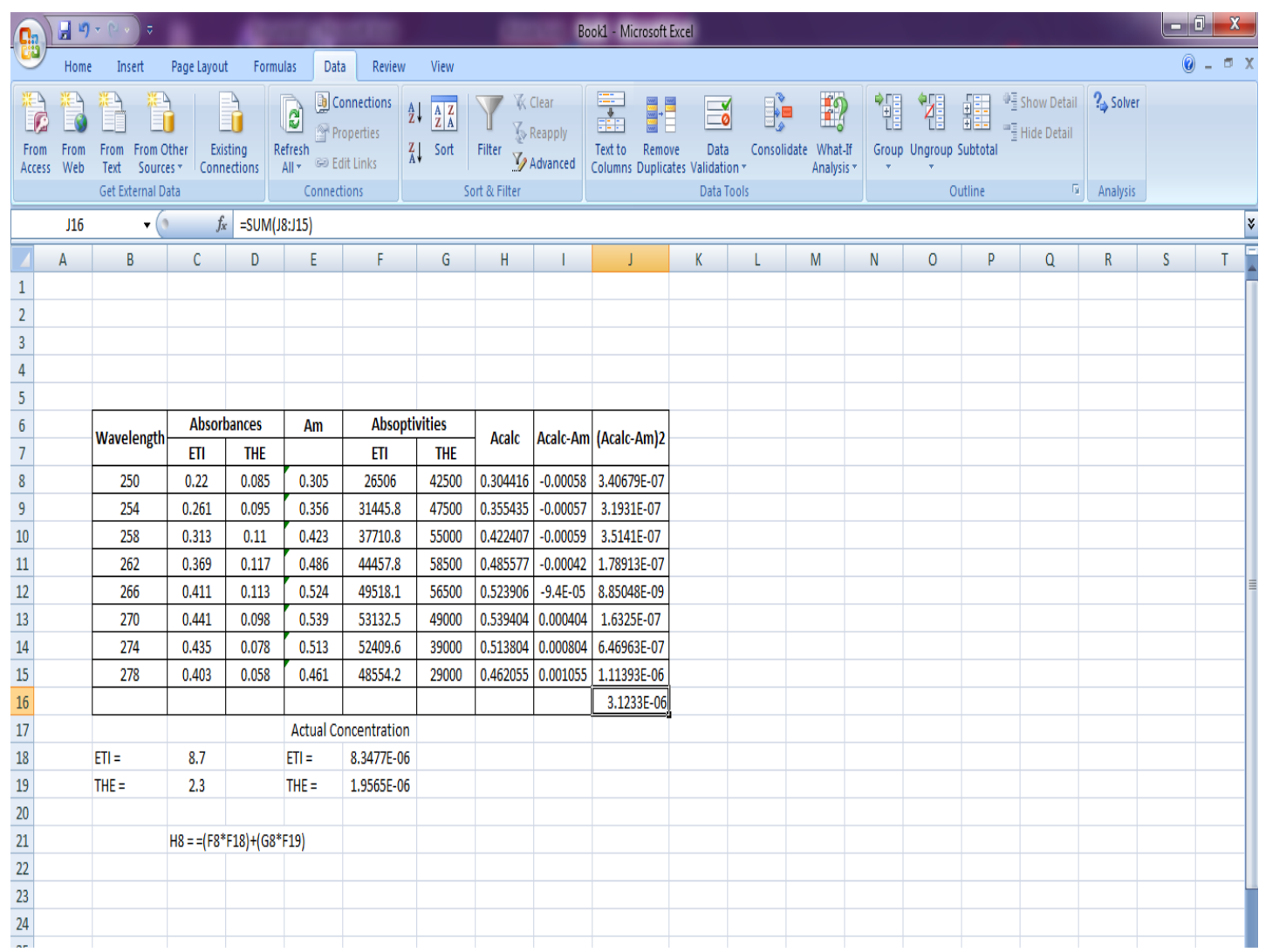

Fig No.3: Screen shot of arranging data into excel sheet 


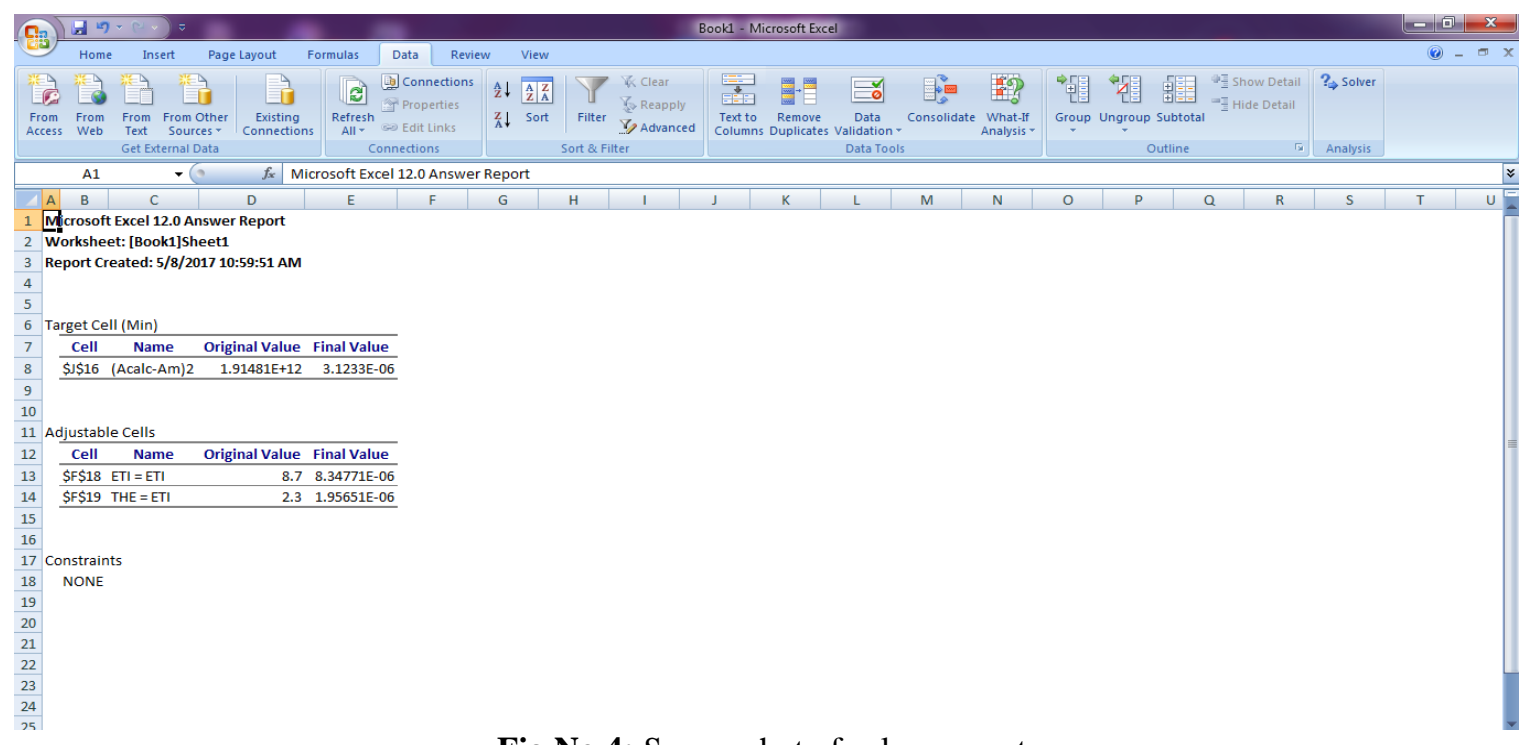

Fig No.4: Screen shot of solver report

The concentration of Ethophylline $\left(\mathrm{C}_{\mathrm{x}}\right)$, Theophylline $\left(\mathrm{C}_{\mathrm{y}}\right)$ present in the given formulation sample were found to be $8.7 \mu \mathrm{g} / \mathrm{ml}, 2.3 \mu \mathrm{g} / \mathrm{ml}$ respectively.

Table No.3:-Percentage assay for the three methods

\begin{tabular}{|c|c|c|c|c|c|c|c|}
\hline & & \multicolumn{2}{|l|}{ TLR } & \multicolumn{2}{|l|}{ CRM } & \multicolumn{2}{|l|}{ MLS } \\
\hline & $\begin{array}{l}\text { Actual } \\
\text { concentration } \\
(\mu \mathrm{g} / \mathrm{mL})\end{array}$ & $\begin{array}{l}\text { Predicted } \\
\text { concentration ( } \\
\mu \mathrm{g} / \mathrm{mL})\end{array}$ & Assay \% & $\begin{array}{l}\text { Predicted } \\
\text { concentration ( } \\
\mu \mathrm{g} / \mathrm{mL})\end{array}$ & Assay \% & $\begin{array}{l}\text { Predicted } \\
\text { concentration ( } \\
\mu \mathrm{g} / \mathrm{mL})\end{array}$ & Assay \% \\
\hline ETO & 8.3 & 8.269 & $99.62 \%$ & 8.426 & $100.5 \%$ & 8.769 & $104.00 \%$ \\
\hline THEO & 2.5 & 2.731 & $109.24 \%$ & 2.733 & $108 \%$ & 2 & $80 \%$ \\
\hline
\end{tabular}

\section{METHOD VALIDATION}

\section{Accuracy :-Table No:-5:-accuracy}

\begin{tabular}{|c|c|c|c|c|}
\hline & & \% RECOVI & & \\
\hline DRUG & PERCENTAGE & Bi -linearity & FOR CRM & FOR MLS \\
\hline \multirow{3}{*}{ ETO } & $85 \%$ & 98.66 & 100.13 & 99.85 \\
\hline & $100 \%$ & 99.10 & 99.75 & 99.72 \\
\hline & $115 \%$ & 100.44 & 99.84 & 99.15 \\
\hline \multirow{3}{*}{ THEO } & $75 \%$ & 98.89 & 100.44 & 99.12 \\
\hline & $100 \%$ & 99.16 & 100.50 & 100.26 \\
\hline & $125 \%$ & 100.26 & 99.86 & 98.98 \\
\hline
\end{tabular}

\section{Linearity and range :-}

Table No. 6:-Linear equation parameters

\begin{tabular}{|c|c|c|c|c|c|c|c|}
\hline \multirow[t]{2}{*}{ Drug } & \multirow{2}{*}{$\begin{array}{l}\text { Wave } \\
\text { length } \\
\text { nm }\end{array}$} & \multicolumn{2}{|c|}{ For TLRC Method } & \multicolumn{4}{|c|}{ For Cramers matrix method(CRM) } \\
\hline & & Linear equation & $\mathbf{R}^{2}$ & $\begin{array}{l}\text { RANGE } \\
\mu \mathrm{g} / \mathrm{mL}\end{array}$ & Linear equation & $\mathbf{R}^{2}$ & $\begin{array}{l}\text { RANGE } \\
\mu \mathrm{g} / \mathrm{mL}\end{array}$ \\
\hline ETO & $\begin{array}{l}271 \\
273\end{array}$ & $\begin{array}{l}y=0.010 x+-0.001 \\
y=0.055 x-0.016\end{array}$ & $\begin{array}{l}0.998 \\
0.968\end{array}$ & $5-9$ & $\begin{array}{l}y=0.010 x+-0.001 \\
y=0.055 x-0.016\end{array}$ & $\begin{array}{l}0.998 \\
0.968\end{array}$ & $5-9$ \\
\hline THEO & $\begin{array}{l}271 \\
273\end{array}$ & $\begin{array}{l}y=0.063 x+-0.008 \\
y=0.010 x+-0.001\end{array}$ & $\begin{array}{l}0.979 \\
0.991\end{array}$ & $1-5$ & $\begin{array}{l}y=0.063 x+0.008 \\
y=0.010 x+0.001\end{array}$ & $\begin{array}{l}0.979 \\
0.991\end{array}$ & $1-5$ \\
\hline
\end{tabular}




\section{PRECISION}

Table No. 7: Percentage RSD for all the methods

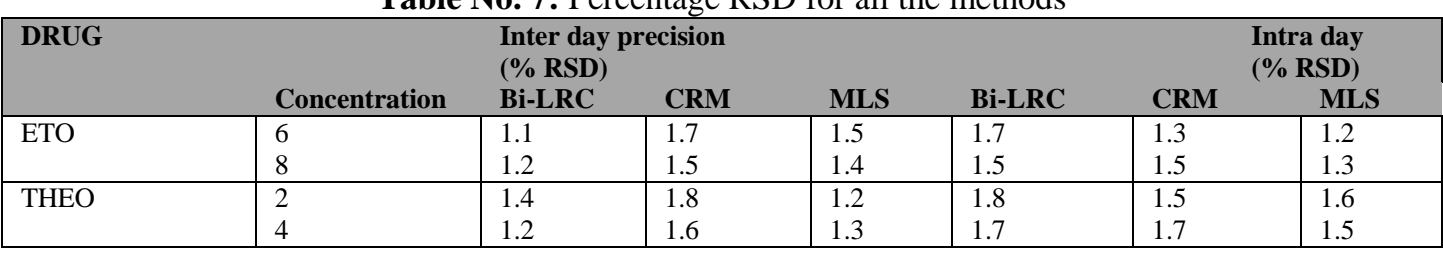

The proposed spectrophotometric method was found to be linear and the data is presented in the Table No 7. The intra-day and inter-day precision values for both the chemo metric designs were presented in Table No 6 Accuracy was performed in terms of the Percent recovery values and the values for Etophylline,Theophylline by all the chemo metric designs were presented in Table No 5 The assay of the commercial formulation of the drugs were performed and their percentage assay values were presented in Table No 3.

\section{Conclusion}

The developed methods neither require any cumbersome separation procedure nor complex derivatization procedures for the analysis of the three drugs and moreover they are effective in minimizing the errors in analysis, simple and economical. Finally it is concluded that the developed methods were simple and accurate can be used in routine analysis.

\section{Acknowledgement}

We acknowledge the management of Chalapathi institute of pharmaceutical sciences, Lam, Guntur for providing the facilities to carry out this research work. We also thank Dr.Reddy's laboratories, Pvt. Ltd, Hyderabad for providing the gift samples of the drugs.

\section{Conflict Of Interest}

This is a non-funding research work. There were no conflicts of interest.

\section{References}

[1]. Chemo metrics and intelligent laboratory systems et.al, Elsevier journal journal, homepage: www.elsevier.com/locate/chemolab.

[2]. M. Katajamaa, M. Oresic, J. Chromatograph.A 1158 (2007) 318-328.

[3]. Chemo metrics in analytical spectroscopy $2^{\text {nd }}$ edition .m.j.adamas

[4]. Chemo metric technique for the optimization of chromatographic system: Simultaneous.HPLC determination of Rosuvastatin, Telmisartan, Ezetimibe and Atorvastatin used in combined cardiovascular therapy V. Sree Janardhanan, et.al King Saud University, and Arabian Journal of Chemistry.

[5]. David Harvey, Modern analytical chemistry, $1^{\text {st }}$ ed. McGraw-Hill; 2000; p. 5-9.

[6]. Mike. J. Adams. Chemo metrics in Analytical Spectroscopy; Royal society of chemistry; 1995; p.155197.

[7]. Naveen Kumar, Ankit Bansal, G.S. Sarma and Ravindra K. Rowal. Chemo metrics tools used in analytical chemistry: An overview; Talanta, 2014 (123); p. 186-199.

[8]. Simultaneous Estimation of Atorvastatin and Aspirin in Bulk and Capsule Dosage Form by Chemo metric Assisted Spectrophotometric Methods.J Young Pharm, 2016; 8(4): 424-429.

[9]. Lakshmi KS, Lakshmi S. Design and Optimization of a Chemo metric-Assisted Spectrophotometric Determination of Telmisartan and Hydrochlorothiazide in Pharmaceutical Dosage Form. J Young Pharm. 2010; 2(1):85-9.

[10]. Sanni Matero. Chemo metric methods in pharmaceutical tablet development and manufacturing unit operations; Publications of the University of Eastern Finland, 2010; p. 5-1.

[11]. Mike. J. Adams. Chemo metrics in Analytical Spectroscopy; Royal society of chemistry; 1995; p.155197.

[12]. Londhe SV,Mulgund SV,Jain KS. Reversed-phase HPLC JAN 2011

[13]. Mr JIVAN RAJARAM PATIL RP-HPLC 2011-2012.

[14]. A. Shankar, Thangarasu Vetrichelvan, Devashya Venkappaya UV-spectrophotometric Detroiter; Sept 2011.

[15]. Indianpharmacopeia vol-1,2-1995. 